\title{
Medication Administration Errors Involving Paediatric In-Patients in a Hospital in Ethiopia
}

\author{
Yemisirach Feleke and Biniyam Girma*
}

School of Pharmacy, Jimma University, P.O Box 378, Jimma, Ethiopia

\begin{abstract}
Purpose: To assess the type and frequency of medication administration errors (MAEs) in the paediatric ward of Jimma University Specialized Hospital (JUSH), Jimma, Oromia Region, southwestern Ethiopia.

Methods: A prospective case-based observational study was performed. The required data were collected by observing the health professionals and attendants in charge of administering medications to in-patients in the three units of the paediatric ward of JUSH from February 18 to March 2, 2009.

Results: A total of 196 (89.9 \%) MAEs were identified from the 218 observations made. From these, $178(90.8 \%)$ occurred with intravenous (IV) bolus medications while $16(8.2 \%)$ of them pertained to oral medications. The most frequent of the MAEs observed was wrong time error with 55 errors or $28.1 \%$ of the total, while 52 (26.5\%) were dose errors and 42 (21.4\%) were due to drugs omitted during drug administration. Furthermore, wrong administration technique errors and unauthorized drug errors were $41(20.9 \%)$ and 6 (3.1\%), respectively. The drug mostly associated with error was gentamicin with 29 errors (31.2\%).

Conclusion: During the study, a high frequency of error was observed. There is a need to modify the way information is handled and shared by professionals as wrong time error was the most implicated error. Attention should also be given to IV medication administration with special emphasis on gentamicin, ampicillin, cloxacillin and crystalline penicillin.
\end{abstract}

Keywords: Medication administration error, Omission error, Wrong dose, Wrong administration technique, Unauthorized drug. 


\section{INTRODUCTION}

Patient's age is the most important risk factor for medication administration errors (MAEs) [1]. As recent evidence from United States indicated, potentially harmful MAEs may be three times more common in the paediatric population than among adults; this suggests that the epidemiologic characteristics of the errors may be different between adults and children [2].

Children and adolescents are at a greater risk than adults for medication errors because they have immature physiology as well as developmental limitations that affect their responsibility to communicate and selfadminister medications. Another important factor is that the great majority of medications are developed in concentrations appropriate for adults. In addition, determining paediatric dosages can be complicated because of the need to calculate the child's weight; therefore, those children who take such medications are at a greater risk of medication error than adults who don't require such calculations [3]. These errors are potentially dangerous as omission of one step or wrong calculation can result in a dose up to 10 times higher than necessary. This can cause serious injury, even death, especially when medication agents have a narrow therapeutic range [1].

According to a study on drug administration error and their determinants in paediatric inpatients in France, wrong time error 192 (36 $\%)$ was the commonest followed by wrong route 102 (10\%), wrong dose $83(15 \%)$, unordered drug 52 (10\%), omission 27 (5\%) and wrong administration or preparation technique 17 (3\%) [4]. In another study in a teaching hospital in India, medication administration for 1286 children were studied. Out of a total of 457 errors $313(68.5 \%)$ errors were detected, amongst which 62 $(13.6 \%)$ were errors related to treatment procedures (administration technique), and $208(45.5 \%)$ were dose errors [5].
In another study, patients in intensive care unit (ICU) were prescribed twice as many medications as non-ICU patients. The Critical Care Safety Study demonstrated that $78 \%$ of serious errors in ICU patients are attributable to medications [6]. A study carried out in a hospital in France showed that of 2009 medication administrations, 132 (6.6\%) were erroneous. The errors were dose error (41), wrong rate administration (21), wrong preparation technique (24), physicochemical incompatibility (19), wrong administration technique (10) and wrong time errors (9) [7].

The most common group of drugs involved in medication error and potential adverse drug events, according to a study in two urban teaching hospitals in the US, were antiinfective agents, analgesics and sedatives, electrolytes and fluids, and bronchodilators [8]. In another study in the United Kingdom (UK), antibiotics constituted the most common drug group involved in medication errors [9]. Injectable medications are of great concern due to the fact that $44 \%$ of potential adverse drug events and $61 \%$ of serious and life threatening errors are associated with IV medications [10]. A study on medication errors in a paediatric teaching hospital in the UK indicates that errors involving the intravenous route were the commonest (44 \%) [9].

The role of the professional pharmacist in Ethiopia is generally limited to the dispensing desks. Furthermore, pharmacist interaction with other health professionals, especially prescribers, does not go beyond obeying their prescription instructions. However, there are ongoing efforts to shift the pharmacist from product-oriented practice to one that is more patient-oriented and the need to imbibe the pharmaceutical care. As a step in this direction, the objective of this study was to quantify the type and frequency of medication administration errors involving paediatric inpatients and to identify the most frequently implicated medications. The results of this study could facilitate the institution of measures to minimize medication errors. 


\section{Setting}

This study was conducted in the paediatric ward of Jimma University Specialized Hospital (JUSH), a teaching hospital located in Jimma town, Oromia Region in southwestern Ethiopia, $335 \mathrm{~km}$ from the national capital, Addis Ababa. JUSH has divisions such as surgery, gynecology and obstetrics, paediatrics, internal medicine, psychiatry, laboratory, tuberculosis, etc. It is a referral hospital with 450 beds where a multidisciplinary team of diverse professionals provides a range of health services. Among these professionals are 17 specialists, 43 general practitioners, 2 health officers, 155 nurses, 16 laboratory technicians, 4 pharmacists and 26 health assistants.

\section{Study design}

A prospective observational case-based study was used. All patients in the three medical units of the paediatric ward were considered for observation during the study period. The health professionals and attendants enrolled in the study were informed of the work prior to commencement but the entire purpose of the study was not disclosed in order to ensure that the findings would be unbiased. Each administration case, whether repeated in a patient or involving a newly admitted patient, was considered as a single new case. The three medical units of the paediatric ward, i.e., Ward A, Critical Ward and Nutritional Resuscitation Unit NRU, were the specific study sites, and the study period spanned 14 consecutive days (February 18 to March 2, 2009) excluding weekends. Ward $A$ is a paediatric medical unit where stable patients and patients discharged from the other two medical units receive further medical care, while Critical Ward is a paediatric medical unit where patients in critical condition are treated. NRU is a paediatric medical unit for malnourished in-patients. All the health professionals and attendants in charge of administering medications to paediatric patients in the three units were observed. All observed medication administrations were made by 9 nurses ( 5 males and 4 females) and the 23 attendants of the patients.

\section{Data collection}

The data collectors were final year degree pharmacy students who were well briefed on how to identify medication administration error. In addition, they each received a written guide which detailed the procedure to be followed.

\section{Definition of errors}

The definitions of the various error types including MAEs were adopted from previous studies in the area. The various errors were defined as in the following subsections.

Medication errors - any preventable events that occur in the process of ordering or delivering a medication regardless of whether an injury or the potential for injury was present [2]

Medication administration error (MAE) - a medication error that occurs while administering a medication to a patient.

Omitted drug error - failure to administer a prescribed medication [11].

Unauthorized drug error - the medication dispensed and/or administered was not authorized by the prescriber [11]

Wrong administration technique error exclusion, or incorrect performance, of a procedure ordered by a prescriber immediately before administration of each dose of a medication [12].

Wrong dose error - medication dose, strength, or quantity different from that prescribed [11].

Wrong time error - there is greater than 1 hour difference between the ordered time and the time the medication is administered [12]. 


\section{Data analysis}

The data collected were cleared, categorized and analyzed according to check lists and standard reference guidelines. SPSS software was used to analyze the data. The statistical analysis was made at $90 \%$ confidence level and with a $10 \%$ margin of error. Multiple administrations were counted as one though two errors might be reported in a single administration. Each error was computed per the total number of administrations observed. Pearson chisquare test was carried out to see if there was any association between the dependent and independent variables.

\section{RESULTS}

As Table 1 shows, more of the patients were in the 1 - 5 years age group (40.4\%) followed by those who were $<1$ year of age $(21.2 \%)$.

Table 1: Age distribution of the children in the paediatric wards

\begin{tabular}{ccccc}
\hline \multirow{2}{*}{$\begin{array}{c}\text { Age } \\
\text { (yr) }\end{array}$} & \multicolumn{3}{c}{ No. of patients } & Total \\
\cline { 2 - 4 } & Ward A & Critical & NRU & \\
\hline$<1$ & 4 & 5 & 2 & $\begin{array}{c}11 \\
(21.15 \%)\end{array}$ \\
$1-5$ & 3 & 11 & 7 & 21 \\
$6-8$ & 4 & 5 & 1 & $\begin{array}{c}(40.4 \%) \\
10 \\
(19.2 \%) \\
11-15\end{array}$ \\
& 6 & 1 & 3 & $\begin{array}{c}10 \\
(19.2 \%)\end{array}$ \\
\hline Total & 17 & 22 & 13 & 52 \\
\hline
\end{tabular}

A total of 218 observations, distributed across the paediatric wards $(62,74$ and 82 observations for Ward A, Critical ward and $\mathrm{NRU}$, respectively), were made on 9 nurses (5 male and 4 female) and 23 attendants who administered medications. A total of 52 patients were covered in the study. Table 2 shows the distribution of the MAEs. Out of a total of 218 observations, 196 (89.9\%) MAEs were identified, with $178(90.8 \%)$ of them occurring during the preparation and administration of IV medications, and 16 (8.2 $\%$ detected on medications administered orally. Among the MAEs detected on IV-bolus medications, 49 (27.5 \%) were random dosing (reported as wrong dose error) and 48 $(27.0 \%)$ wrong time errors. Unauthorized drug errors (6 or $3.4 \%$ ) were the least of the observed MAEs on IV-bolus medication administrations. Out of the $16(8.2 \%)$ MAEs detected on oral medication administrations, wrong time error accounted for 7 of them $(43.8 \%)$ while 5 (31.3\%) were wrong administration technique errors and 1 (6.3\%) was omitted drug administration error.

Table 2: Distribution of observed MAEs according to route of administration

\begin{tabular}{|c|c|c|c|c|}
\hline \multirow{2}{*}{$\begin{array}{l}\text { Category of } \\
\text { MAEs }\end{array}$} & \multicolumn{3}{|c|}{$\begin{array}{l}\text { Route of drug } \\
\text { administration }\end{array}$} & \multirow[t]{2}{*}{ Total } \\
\hline & IV bolus & Oral & Others & \\
\hline $\begin{array}{l}\text { Wrong dose } \\
\text { error }\end{array}$ & $\begin{array}{c}49 \\
(27.5 \%)\end{array}$ & $\begin{array}{c}3 \\
(18.8 \%)\end{array}$ & - & \\
\hline $\begin{array}{l}\text { Wrong time } \\
\text { error }\end{array}$ & $\begin{array}{c}48 \\
(27.0 \%)\end{array}$ & $\begin{array}{c}7 \\
(43.8 \%)\end{array}$ & - & 55 \\
\hline $\begin{array}{l}\text { Wrong } \\
\text { administration } \\
\text { technique error }\end{array}$ & $\begin{array}{c}36 \\
(20.2 \%)\end{array}$ & $\begin{array}{c}5 \\
(31.3 \%)\end{array}$ & - & 41 \\
\hline $\begin{array}{l}\text { Unauthorized } \\
\text { drug error }\end{array}$ & $\begin{array}{c}6 \\
(3.4 \%)\end{array}$ & - & - & 6 \\
\hline $\begin{array}{l}\text { Omitted drug } \\
\text { error }\end{array}$ & $\begin{array}{c}39 \\
(21.9 \%)\end{array}$ & $\begin{array}{c}1 \\
(6.3 \%)\end{array}$ & $\begin{array}{c}2 \\
(100 \%)\end{array}$ & 42 \\
\hline Total & $\begin{array}{c}178 \\
(90.8 \%)\end{array}$ & $\begin{array}{c}16 \\
(8.3 \%)\end{array}$ & $\begin{array}{c}2 \\
(1.02 \%)\end{array}$ & 196 \\
\hline
\end{tabular}

Examples of the categories of medication administration errors observed are indicated in Table 3. The distribution of errors among the various categories as well as amongst the units of the paediatric ward is shown in Table 4. The most frequent of the MAEs was wrong time error (55/196, $28.1 \%)$; there were also $52(26.5 \%)$ wrong dose errors and 42 (21.4 $\%)$ omitted drug administration errors. Wrong administration technique errors and unauthorized drug errors accounted for 41 $(20.9 \%)$ and $6(3.1 \%)$, respectively. The number of errors that occurred in Ward $A$ was 
$69(35.2 \%)$ followed closely by Critical ward with $64(32.7 \%)$, and NRU $63(32.1 \%)$. Thus, there were no significant difference between the wards in terms of frequency of MAEs.

Table 3: Examples of observed categories of medication administration errors (MAEs)

\begin{tabular}{|c|c|}
\hline $\begin{array}{l}\text { Category of } \\
\text { error }\end{array}$ & Example \\
\hline Wrong time error & $\begin{array}{l}\text { Furosemide } 100 \mathrm{mg} / \mathrm{ml} \text { IV bid } \\
\text { was ordered for a } 2 \text { yr old } \\
\text { male patient but the } \\
\text { medication to be given at } \\
12: 00 \mathrm{pm} \text { was actually given } \\
\text { at } 3: 52 \mathrm{pm} \text {. }\end{array}$ \\
\hline $\begin{array}{l}\text { Wrong dose } \\
\text { error }\end{array}$ & $\begin{array}{l}\text { A } 625,000 \text { IU of crystalline } \\
\text { penicillin was prescribed for } \\
\text { a } 4 \text { yr old male patient but } \\
\text { the administered dose was } 1 \\
\text { vial, i.e., } 1,000,000 \text { IU }\end{array}$ \\
\hline $\begin{array}{l}\text { Wrong } \\
\text { administration } \\
\text { technique error }\end{array}$ & $\begin{array}{l}\text { Gentamicin IV bolus, a single } \\
\text { adult dose preparation was } \\
\text { being given in divided doses } \\
\text { with the ampoule kept open } \\
\text { for re-use }\end{array}$ \\
\hline $\begin{array}{l}\text { Unauthorized } \\
\text { drug error }\end{array}$ & $\begin{array}{l}\text { A } 21 / 2 \text { yr old male patient } \\
\text { was prescribed } 500 \mathrm{mg} \\
\text { ampicillin IV qid and } \\
\text { salbutamol syrup, } 0.4 \mathrm{mg} \text { po } \\
\text { tid but received cloxacillin in } \\
\text { addition }\end{array}$ \\
\hline $\begin{array}{l}\text { Omitted drug } \\
\text { error }\end{array}$ & $\begin{array}{l}\text { A } 5 \text { yr old female patient was } \\
\text { prsecribed intermittent } \\
\text { intranasal } \mathrm{O}_{2} \text { but was } \\
\text { discontinued. }\end{array}$ \\
\hline
\end{tabular}

The distribution of drugs associated with MAEs is listed in Table 5. The most common class of drugs administered was antibiotics, with ampicillin $(27.1 \%)$, cloxacillin $(24.5 \%)$, and gentamicin $(20.2 \%)$ accounting for the highest incidence of errors in this class. Salbutamol syrup, amoxicillin and captopril were the medications given orally (Table 5).

\section{DISCUSSION}

The results obtained reveal that MAEs are prevalent in the paediatric units of the hospital where the study took place. Thus, attention should not only focus on sick and Table 4: Distribution of MAEs by category and ward unit

\begin{tabular}{|c|c|c|c|c|}
\hline \multirow{2}{*}{$\begin{array}{l}\text { Category of } \\
\text { MAEs }\end{array}$} & \multicolumn{3}{|c|}{ Paediatric unit } & \multirow[b]{2}{*}{ Total } \\
\hline & $\begin{array}{c}\text { Ward A } \\
(\%)\end{array}$ & $\begin{array}{c}\text { Critical } \\
\text { ward (\%) }\end{array}$ & $\begin{array}{c}\text { NRU } \\
(\%)\end{array}$ & \\
\hline $\begin{array}{l}\text { Wrong dose } \\
\text { error }\end{array}$ & $\begin{array}{l}13 \\
(25)\end{array}$ & $\begin{array}{l}21 \\
(40.4)\end{array}$ & $\begin{array}{l}18 \\
(34.6)\end{array}$ & $\begin{array}{l}52 \\
(26.5 \%)\end{array}$ \\
\hline $\begin{array}{l}\text { Wrong time } \\
\text { error }\end{array}$ & $\begin{array}{l}28 \\
(50.19)\end{array}$ & $\begin{array}{l}13 \\
(23.6)\end{array}$ & $\begin{array}{l}14 \\
(24.5)\end{array}$ & $\begin{array}{l}55 \\
(28.1 \%)\end{array}$ \\
\hline $\begin{array}{l}\text { Wrong } \\
\text { administra- } \\
\text { tion } \\
\text { technique } \\
\text { error }\end{array}$ & $\begin{array}{l}12 \\
(29.27)\end{array}$ & $\begin{array}{l}11 \\
(26.8)\end{array}$ & $\begin{array}{l}18 \\
(43.9)\end{array}$ & $\begin{array}{l}41 \\
(20.9 \%)\end{array}$ \\
\hline $\begin{array}{l}\text { Unautho- } \\
\text { rized drug } \\
\text { error }\end{array}$ & $\begin{array}{l}3 \\
(50.00)\end{array}$ & $3(50.0)$ & - & $\begin{array}{l}6 \\
(3.1 \%)\end{array}$ \\
\hline $\begin{array}{l}\text { Omitted drug } \\
\text { error }\end{array}$ & $\begin{array}{l}13 \\
(30.95)\end{array}$ & $\begin{array}{l}16 \\
(38.9)\end{array}$ & $\begin{array}{l}13 \\
(30.9)\end{array}$ & $\begin{array}{l}42 \\
(21.4 \%)\end{array}$ \\
\hline Total & 69 & 64 & 63 & $\begin{array}{l}196 \\
(100 \%)\end{array}$ \\
\hline
\end{tabular}

Table 5: Drugs associated with medication errors in paediatric in-patients

\begin{tabular}{|c|c|c|}
\hline Drug & $\begin{array}{l}\text { Frequency of } \\
\text { medication } \\
\text { administration }\end{array}$ & $\begin{array}{l}\text { Frequency } \\
\text { of MAE }\end{array}$ \\
\hline Ampicillin & $51(27.1 \%)$ & $23(24.7 \%)$ \\
\hline Cloxacillin & $46(24.5 \%)$ & $15(16.1 \%)$ \\
\hline $\begin{array}{l}\text { Crystalline } \\
\text { penicillin }\end{array}$ & 22 (11.7\%) & $11(11.8 \%)$ \\
\hline Chloramphenicol & $11(5.9 \%)$ & $7(7.5 \%)$ \\
\hline Ceftriaxone & $7(3.7 \%)$ & $3(3.2 \%)$ \\
\hline Furosemide & $5(2.6 \%)$ & $2(2.2 \%)$ \\
\hline Gentamicin & $38(20.2 \%)$ & $29(31.2 \%)$ \\
\hline Others & $8(4.2 \%)$ & $3(3.2 \%)$ \\
\hline Total & 188 & $93(100 \%)$ \\
\hline
\end{tabular}

untreated patients but also on those on medication.

Overall, a high prevalence $(89.9 \%)$ of MAEs was found and there were also medication administration cases with more than one error but which were reported as a single case. A study in India reported an MAE rate 
of $68.5 \%$ [5]. It seems that the error rate was significantly higher in this study than stated in the Indian report.

In our study, wrong time error was the most frequent of the identified MAEs, accounting for $28.1 \%$. A study in Buenos Aires, Argentina also found wrong time, in addition to omission of medications, to be the most frequent errors [1]. Wrong time error is usually associated with information gap between health professionals working on a case [11]. Such high errors may be related to the fact that patient cards are not handled properly which could be responsible for such a gap.

According to a United States study, incorrect dosing $(47 \%)$ was the most commonly reported MAE [13], unlike in our study, where wrong dose errors constituted $26.5 \%$ and was the second largest error detected, with $94.2 \%$ originating from IV bolus medications. The figure for wrong dose error obtained by us is, however, much lower than that from a teaching hospital in India which recorded $45.5 \%$ [5]. Increased work load is implicated as a major contributing factor for such types of errors [11]. Therefore, such a hospital may need to increase the number of professionals in charge of medication administration.

It should be noted that omission of one step or a wrong calculation can result in a dose that is 10 times higher than necessary. This can produce severe injury or even death, especially when medication agents have a narrow therapeutic range [1]. The fact that gentamicin was one of the drugs most commonly associated with error and is also a highly toxic drug with the dose error identified mostly with intravenous administration, should be of great concern. Omission errors are usually associated with inexperience and knowledge deficit [11], their occurrence being the third largest and may even be higher than in many other countries. This calls for intensified effort in the area of educating and updating staff members.
Medication administrations which did not strictly follow standard or ordered procedures were termed wrong administration technique errors and constituted a fifth of the total Nearly $90 \%$ of these were detected on IVbolus medications which had to be prepared. The figure is higher than the one record in India where a few were errors related to treatment procedures (administration techniques) [5].

There were $3.1 \%$ of cases where unordered medications were administered to a patient. This contrasts with a study in Paris, France where the figure was $15 \%$ [4]. Comparatively therefore,, the incidence of unauthorized drug error found in this study is minor.

In about a fifth of all MAEs, the health professionals or attendants in charge of medication administration failed to administer a drug to a particular patient, i.e., omission error. Since most of the drugs administered were antibiotics, omission of the drugs might have had a negative outcome, and could lead to drug resistance which has become increasingly worrisome.

The drugs mostly involved with errors were antibiotics with gentamicin with three-quarters of all such observations and ampicillin coming a distant second with nearly a quarter of such observation. A similarly study on medication errors in a paediatric teaching hospital in UK indicated that antibiotics were also the most frequently encountered drugs in errors [9].

Injectable medications are often of great concern. Besides being highly associated with adverse events, they are also commonly linked with errors [10]. Such IV errors also featured prominently in our study. But no association was found between the routes of administration and MAEs ( $p=0.135>0.05)$. This suggests that the problem with oral doses is as bad as that with parenterals. The extent of IV errors, which was nine-tenths in our study, was almost twice as high as that found in a study in a UK paediatric hospital 
which was less than half of their observations [9].

The distribution of error may vary among different units of the paediatric ward for several reasons. The intensive care unit (ICU) in general consumes drugs twice as much as non-ICU [6]. Therefore, it is logical to expect a higher level of errors in ICU. In this study, however, the incidence of error was higher in Ward A (a non-ICU) than in Critical ward which is an ICU in spite of the fact that Ward A presented fewer observations. Nevertheless, no significant association was found between the paediatric ward units and the extent of MAEs ( $p=0.066$ $>0.05$ ).

Although this study does not clearly show the clinical significance of the errors observed, the large number of paediatric in-patients receiving a high proportion of intravenous drug administrations in which $40 \%$ of the patients were aged 1-5 years and therefore, have an immature physiology that cannot effectively resist infections, IV drug errors may constitute a potential source of serious harm to patients. Consequently, risk reduction strategies would need to be developed to mitigate these errors.

\section{CONCLUSION}

Although this study did not assess the clinical significance of the MAEs investigated, the fact that they were pronounced in the lowest age group of children and with intravenous medications suggest that the errors could pose serious problems in paediatric therapy. Therefore, appropriate measures need to be put in place to minimize these errors while further studies should be conducted not only to better understand the ramifications of MAEs but also to determine effective ways to tackle the challenges they pose.

\section{REFERENCES}

1. Otero P, Leyton A, Mariani G, Ceriani Cernadas JM. Patient Safety Committee. Medication errors in pediatric in patients; prevalence and results of a prevention program. Pediatrics 2008; 122(3): e737-743

2. Committee on drugs and committee on hospital care. Prevention of medication errors in the pediatric inpatient setting. policy statement. Pediatrics 2003; 112(2): 431-436

3. Hughes RG, Edgerton EA. Reducing pediatric medication errors: children are especially at risk for medication errors. Am J Nurs 2005; 105(5): $79-80$

4. Prot $S$ et al. Drug administration errors and their determinants in pediatric in-patients. Int J Qual Health Care 2005; 17(5): 381-389

5. Parihar M, Passi GR. Medical errors in pediatric practice. Indian Pediatr 2008; 45(7): 586-589

6. Kane-Gills $S$, Weber RJ. Principles and practices of medication safety in the ICU. Crit Care Clin 2006; 22: 273-290

7. Tissot $E$, cornette $C$, Demoly $P$, Jacquet $M$, Barale $F$, Capellier G. Medication errors at the administration stage in an intensive care unit; Intensive Care Med 1999; 25(40): 353-359

8. Kaushal R, Bates DW, Landrigan C, McKenna KJ, Clapp MD, Federico F, Goldmann DA. Medication errors and adverse drug events in pediatric inpatients. JAMA 2001; 285(16): 2114-2120

9. Ross LM, Wallace J, Paton JY. Medication errors in a pediatric teaching hospital in UK. Arch Dis Child 2000; 83(6): 492-497

10. Hatcher I, Sullivan M, Hutchinsom J. Thurman $S$, Gaffney FA. An intravenous medication safety system: preventing high risk medication errors at the point of care. J Nurs Adm 2004; 34: $437-439$

11. Medication Errors, International Council of Nurses. ICN; c1899-2010 [cited 2 Feb 2010]. Available from: http://www.icn.ch/matters_errors.htm

12. Kenneth $N$, Elizabeth A, Ginette A, David W, Robert $L$. Medication errors observed in 36 health care facilities. ARCH INTEN MED 2002; 162172

13. Crowley E, Williams $R$, Cousins D. Medication errors in children: a descriptive summary of medication error reports submitted to the United States Pharmacopeia. Curr Ther Res.2001; 26: 627-640 